\title{
GENETIC VARIATION AT THE ALCOHOL DEHYDROGENASE LOCUS IN NATURALPOPULATIONS OF THE SEAWEED FLY, COELOPA FRIGIDA
}

\author{
R. K. BUTLIN, P. M. COLLINS, S. J. SKEVINGTON and T. H. DAY \\ Department of Genetics, University of Nottingham, University Park, \\ Nottingham, NG7 2RD
}

Received 15.vi.81

\section{SUMMARY}

\begin{abstract}
Samples of the seaweed fly, Coelopa frigida, from six populations widely spaced around the English coast were collected during 1974-76 and again in 1979-80. Gene frequencies at the Alcohol dehydrogenase (Adh) locus were found not to vary significantly between sites, nor over the five year period of their study. Genotype distributions are compared with Hardy-Weinberg expectations and show consistent, mostly significant, differences.

These results are interpreted in the light of an association between the $A d h$ locus and a chromosomal inversion polymorphism. It is argued that the remarkable geographical uniformity must indicate the presence of strong selection, probably taking the form of heterokaryotypic advantage.
\end{abstract}

\section{INTRODUCTION}

ONE of the central problems facing population geneticists is the maintenance of genetic variation in natural populations. Most agree that two types of processes are operating. The selectionist school emphasises the importance of non-random reproduction and mortality, while the so-called "neutralists" assert that random processes such as founder effect and drift play a major role. The critical question for any particular polymorphism is the relative contributions of random and non-random processes.

The degree of difference actually found between populations is particularly informative. At one extreme a pattern of random differences would be predicted if selection played a negligible role; at the other extreme complete uniformity provides strong evidence that selective processes predominate. This randomness, or uniformity, refers both to comparisons of geographically separated populations and to comparisons between populations sampled at successive time intervals. If populations remain unchanged, or if they all change in a uniform way over many generations, then this must be taken as evidence of natural selection.

While there is still an active debate over the relatively recent data on enzyme polymorphisms (see the reviews by Wright, 1978; and Harris, 1980), the maintenance of chromosomal polymorphisms has from the earliest days (Wright and Dobzhansky, 1946) been less controversial. The case for selection acting on chromosomal inversions has been consistently more convincing (da Cunha, 1955; Lewontin and White, 1960; Dobzhansky, 1971; Lewontin, 1974; Anderson et al., 1975). Here we report data on an enzyme polymorphism that is known to be very tightly associated with a chromosomal inversion.

The seaweed fly, Coelopa frigida, is an acalypterate dipteran that lives in piles of decaying seaweed cast up on beaches by tides and winds. Its 
ecology has been studied by Egglishaw (1960), Dobson (1974a, b) and Surver (1974). C. frigida is polymorphic for several chromosomal rearrangements (Philip, 1958, 1966; Aziz, 1975). A polymorphism at the alcohol dehydrogenase locus $(A d h)$ (Day, 1980; Day and Buckley, 1980) is strongly associated with the $\alpha / \beta$ inversion system on chromosome $I$. The evidence for this association is presented in an accompanying paper (Day et al., 1982). Here we report comparisons of the gene and genotype frequencies at the $A d h$ locus in six populations distantly located around the British coast. The populations were sampled over a $16-$ month period in 1974-76 and approximately five years later in 1979-80. These comparisons indicate that there is remarkably little variation between populations and that the equilibrium frequencies have not changed over the five-year period. However, while this study did not set out to explore other types of temporal change, there is a strong suggestion from the data that there may be a seasonal fluctuation in the frequencies of inversions.

\section{MATERIALS AND METHODS}

\section{(i) Collection of samples}

Samples of Coelopa frigida were taken from wrack beds at the sites, and on the dates, given in table 1. In order to obtain comparable samples of Coelopa frigida from different sites and at different times we used a standardised technique for collecting from natural populations. This technique had to take into account the variation in development times of

TABLE 1

Allele frequencies at the alcohol dehydrogenase locus

\begin{tabular}{|c|c|c|c|c|c|}
\hline Sampling site* & $\begin{array}{c}\text { Date of } \\
\text { sampling }\end{array}$ & $B$ & $\begin{array}{c}\text { Adh allele } \\
C\end{array}$ & $D$ & $\begin{array}{c}\text { Sample } \\
\text { size } \dagger\end{array}$ \\
\hline $\begin{array}{l}\text { Beer } \\
\quad \text { (Devon) } \\
\text { (SY229890) }\end{array}$ & $\begin{array}{l}\text { Oct } 1974 \\
\text { Oct } 1979\end{array}$ & $\begin{array}{l}0.33(0.03) \\
0.40(0.02)\end{array}$ & $\begin{array}{l}0.15(0.02) \\
0.07(0.01)\end{array}$ & $\begin{array}{l}0.52(0.03) \\
0.53(0.02)\end{array}$ & $\begin{array}{l}146 \\
281\end{array}$ \\
\hline $\begin{array}{l}\text { Portland } \\
\text { (Dorset) } \\
\text { (SY683687) }\end{array}$ & $\begin{array}{l}\text { Nov } 1974 \\
\text { Aug } 1979\end{array}$ & $\begin{array}{l}0.33(0.03) \\
0.40(0.02)\end{array}$ & $\begin{array}{l}0.12(0.02) \\
0.09(0.01)\end{array}$ & $\begin{array}{l}0.55(0.03) \\
0.52(0.02)\end{array}$ & $\begin{array}{l}115 \\
253\end{array}$ \\
\hline $\begin{array}{l}\text { Flamborough } \\
\text { (Humberside) } \\
\text { (TA255708) }\end{array}$ & $\begin{array}{l}\text { Feb } 1975 \\
\text { Aug } 1979\end{array}$ & $\begin{array}{l}0.35(0.03) \\
0.40(0.02)\end{array}$ & $\begin{array}{l}0.10(0.02) \\
0.16(0.02)\end{array}$ & $\begin{array}{l}0.55(0.03) \\
0.44(0.02)\end{array}$ & $\begin{array}{l}177 \\
265\end{array}$ \\
\hline $\begin{array}{l}\text { Robin Hood's Bay } \\
\text { (North Yorkshire) } \\
\text { (NZ954048) }\end{array}$ & $\begin{array}{l}\text { Mar } 1975 \\
\text { Oct } 1979\end{array}$ & $\begin{array}{l}0.37(0.02) \\
0.43(0.02)\end{array}$ & $\begin{array}{l}0.10(0.01) \\
0.16(0.02)\end{array}$ & $\begin{array}{l}0.54(0.02) \\
0.41(0.02)\end{array}$ & $\begin{array}{l}216 \\
273\end{array}$ \\
\hline $\begin{array}{l}\text { St. Mary's Island } \\
\text { (Tyne and Wear) } \\
\text { (NZ350753) }\end{array}$ & $\begin{array}{l}\text { Oct } 1975 \\
\text { Nov } 1979\end{array}$ & $\begin{array}{l}0.40(0.02) \\
0.33(0.02)\end{array}$ & $\begin{array}{l}0.06(0.01) \\
0.14(0.01)\end{array}$ & $\begin{array}{l}0.53(0.02) \\
0.53(0.02)\end{array}$ & $\begin{array}{l}354 \\
268\end{array}$ \\
\hline $\begin{array}{l}\text { Rustington } \\
\text { (West Sussex) }\end{array}$ & $\begin{array}{l}\text { Jan } 1976 \\
\text { Oct } 1979\end{array}$ & $\begin{array}{l}0.36(0.02) \\
0.42(0.02)\end{array}$ & $\begin{array}{l}0.07(0.01) \\
0.08(0.01)\end{array}$ & $\begin{array}{l}0.57(0.02) \\
0.51(0.02)\end{array}$ & $\begin{array}{l}429 \\
281\end{array}$ \\
\hline
\end{tabular}

(TV049014)

* The exact location of each collecting site is given as the Ordnance Survey map reference.

† The sample size is the total number of individuals excluding animals carrying $A d h-A$ or $E$ alleles. The figure in parenthesis following each allele frequency is the standard error of that frequency (given by: $\sqrt{p(1-p) / n}$ where $p$ is the frequency of the allele, and $n$ the total number of alleles sampled). 
individuals of different $A d h$ genotypes reported by Day et al. (1980), and the aggregation of larvae in family groups observed by Burnet (1961). The method used was to collect larvae from wrack beds in which pupation had not yet begun. This avoided any bias due to the early emergence of some genotypes. At least 20 handfuls of seaweed containing larvae were taken from the wrack bed at widely spaced points to avoid over-representation of individual family aggregates. The whole sample was placed in a plastic tank $(30 \times 20 \times 20 \mathrm{~cm})$ fitted with a hardboard lid and nylon gauze sleeve through which flies could be removed.

In the series of samples taken during 1974-76 and the samples taken in Portland in 1979 , these tanks of seaweed were maintained at $18^{\circ} \mathrm{C}$ in the laboratory, and adult flies were collected daily until no more emerged. The daily samples were then mixed and a sub-sample taken for electrophoresis. There are a number of reasons why we subsequently considered this method might yield a distorted estimate of the gene frequency. There may be selective mortality occurring in the collection tank where typically there are 2000-5000 larvae. Failure to collect the later emerging flies (because of selective death) would clearly bias the results in favour of the fast developing genotypes. Furthermore, if adults lay eggs in the tank, as they invariably do, a second generation will develop and start emerging before collection of the first generation is complete.

In an effort to avoid these problems, a modified sampling technique was used with the 1979 samples. The larvae collected from the wild were allowed to grow in the laboratory until pupation began, at which time most larvae were large enough for electrophoresis. A handful of seaweed was removed from the tank and all larvae and pupae were collected from it. This sub-sample was used for electrophoresis. The three samples collected in 1980 were sub-sampled by both the "adult" and "pre-adult" methods.

\section{(ii) Electrophoresis}

The preparation of homogenates and their electrophoresis in horizontal starch gels were carried out as described by Day and Buckley (1980). Gels were stained by the agar overlay technique using the following staining mixture: $10 \mathrm{ml} 0 \cdot 1 \mathrm{M}$ Tris- $\mathrm{HCl}$ buffer $p \mathrm{H} \mathrm{8.6,5} \mathrm{ml}$ propan-2-ol, $4 \mathrm{ml} \mathrm{NAD}$ $(25 \mathrm{mg} / \mathrm{ml}), \quad 4 \mathrm{ml}$ nitro-blue-tetrazolium (NBT) $(10 \mathrm{mg} / \mathrm{ml}), 2 \mathrm{ml}$ phenazine methosulphate (PMS) $(2 \mathrm{mg} / \mathrm{ml})$ and $25 \mathrm{ml} 2 \% \mathrm{w} / \mathrm{v}$ agar (NAD, NBT, and PMS were dissolved in distilled water). Gels were incubated at $37^{\circ} \mathrm{C}$ in the dark for about 20 minutes. Chemicals were obtained from the following suppliers: propan-2-ol from Fisons (Loughborough, U.K.); NAD from Boehringer (Mannheim, W. Germany); NBT and PMS from Sigma Chemicals Co. Ltd. (Poole, U.K.); Agar No. 1 from Oxoid Ltd. (Basingstoke, U.K.)

\section{(iii) Analysis of deviance}

The observed allele frequencies were arranged for analysis into either two year groups or two seasonal groups. The year groups used were October 1974 to January 1976, and August 1979 to November 1979. The seasonal groups were April to October and November to March irrespective of year. 
The observations were fitted to a generalised linear model (Nelder and Wedderburn, 1972) with a logit transformation and binomial errors, using the "Genstat" computer program (copyright owned by Lawes Agricultural Trust, Rothamstead Experimental Station, Harpenden, Hertfordshire, U.K.).

This analysis generates the ratio of the estimated variation resulting from one factor (site, year or season) to the estimated residual variation. This ratio is approximately distributed as $F$. As the statistical tests used were only one tailed, no probability values can be derived when $F$ is less than 1 . The probability is then inevitably non-significant.

\section{Results}

Five alleles have been observed at the $A d h$ locus, designated $A$ to $E$. Under the conditions used, the $A A$ allozyme is the most anodally migrating and the $E E$ allozyme moves slightly towards the cathode. The isozyme patterns and their genetics have been described in detail by Day and Buckley (1980). The highest frequencies in any population of $A d h-A$ and $E$ are 0.004 and 0.005 respectively, and individuals carrying either of these alleles have been omitted from the analysis. This amounts to an overall loss of just over 0.4 per cent of the data.

\section{(i) Analysis of allele frequencies}

The frequencies of the $A d h-B,-C$ and $-D$ alleles $(f B, f C$ and $f D$ ) are given in table 1 . The first striking feature is the similarity in allele frequencies between populations (for $f B, F_{5,5}=0.18$; for $f C, F_{5,5}=0.69$; for $f D, F_{5,5}=$ $1.48, p>0.2$ ). The test used an analysis of deviance (see Materials and Methods). $f B$ ranges from $0.33-0.43, f C$ ranges from $0.06-0.16$ and $f D$ from $0.41-0.57$. This geographical uniformity is even greater when the populations are only compared within the year groups 1974-76 and 1979.

When the allele frequencies are compared over the year groups-a period of 3-5 years- $f D$ is just significantly different, but both $f B$ and $f C$ are not (for $f B, F_{1,5}=2.9, p>0.1$; for $f C, F_{1,5}=1 \cdot 8, p>0.2$ and for $f D$, $F_{1,5}=6.4, p<0.05$ ). However $f B$ is higher in 1979 at all sites except $S t$. Mary's Island and Beer, where there is virtually no change. To explore further this suggestion of a temporal trend, we have grouped the data into summer (April to October) and winter (November to March) samples. $f B$ can then be seen to be significantly higher in the summer months than in winter at each of the five sites from which samples were taken in both seasons (for $f B, F_{1,5}=21.9, p<0.01 ; f D, F_{1,5}=8.5, p<0.05$ ). $f C$ shows no consistent change between years, nor between seasons.

It is possible that these differences are artefacts due to the change in sampling method. Perhaps the "pre-adult" method of sampling used in 1979 , and including all but one of the "summer" samples, gives a higher estimate of $f B$ than does the "adult" method used in 1974-76. In order to test if this was so, the populations at Portland and St. Mary's Island were re-sampled and an additional sample was collected from Barn's Ness in Southern Scotland. Each sample was divided into two halves and the allele frequencies from one half determined using the pre-adult method and from the other using the adult method. The two methods gave similar results (table 2) for the St. Mary's Island and Barn's Ness samples, but not 


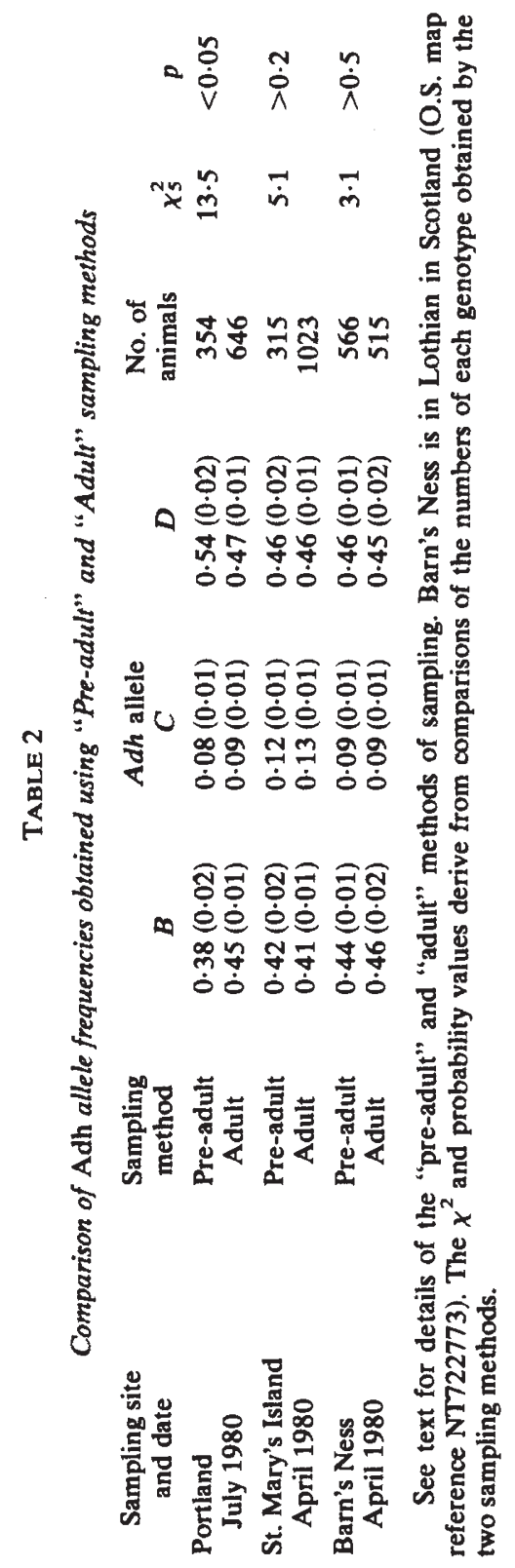


for the Portland sample. However in this sample the difference between methods is in the wrong direction to account for the apparent temporal change. The adult method (the one used in 1979) gives a lower estimate of $f B$, whereas a higher value was actually observed at most sites in that year. Thus if there is an error introduced by changing sampling methods it cannot account for the observed differences between the summer and winter samples. If anything these differences will have been underestimated.

The three samples taken in 1980 all have a high $f B$. As these samples were all taken in the summer months, they are consistent both with the suggestion of a steady increase in $f B$ with time, and with the possibility of an annual cycle in allele frequencies.

\section{(ii) Analysis of genotype frequencies}

The observed genotype distributions have been compared with the distributions expected if the populations were in Hardy-Weinberg equilibrium (table 3). (The pairs of 1980 samples are counted as single samples in the following discussion. The same conclusions are reached whichever sampling method is used.) Eleven of the 15 samples show significant deviations from Hardy-Weinberg expectations. In almost every population there is an excess of $B D$ heterozygotes and a deficiency of $B B$ and $D D$ homozygotes. The deviations from expectation are expressed in table 3 as the ratio of observed numbers to expected numbers. It can be seen that the mean excess of $B D$ 's is almost 20 per cent, and the deficiencies of $B B$ 's and $D D$ 's are 19 per cent and 13 per cent respectively. Furthermore, the very low standard deviations of these means reflect the uniformity between samples. The simplest interpretation of these results is that there is strong and consistent heterozygous advantage.

When the genotypes involving the $A d h-C$ allele are considered the picture becomes less clear. There is a consistent excess of $C C$ homozygotes although its magnitude varies considerably. This might simply be a consequence of the very low numbers of animals with this genotype (most samples less than 10). There is also a consistent 20 per cent deficiency of $B C$ heterozygotes and a modest deficiency (7 per cent) of $C D$ heterozygotes. There is no obvious correspondence between the $C C$ excess and either the $B D$ excess or the $B B$ and $D D$ deficiencies. The excess of $C C$ homozygotes is particularly puzzling. To an untrained observer the $C C$ zymograms could be confused with the $B D$ pattern, but we are confident that mis-scoring of the gels in this way is not the explanation. Perhaps the $C C$ animals really are at a selective advantage and $B C$ 's at a counteracting disadvantage. If this is so then the genotypes at the $A d h$ locus must have a curious array of fitnesses. Consideration of the association of this locus with a chromosomal inversion does not help us to clarify the situation.

\section{Discussion}

The $A d h$ locus in $C$. frigida has been shown to be in strong linkage disequilibrium with two other loci, Esterase II and Peptidase I (Collins, 1978 ) as well as with a chromosomal inversion polymorphism on chromosome I (Philip, 1966; Day et al., 1982). The $A d h-B$ allele is almost invariably found with the $\alpha$ sequence, and the $D$ allele with the $\beta$ sequence, 


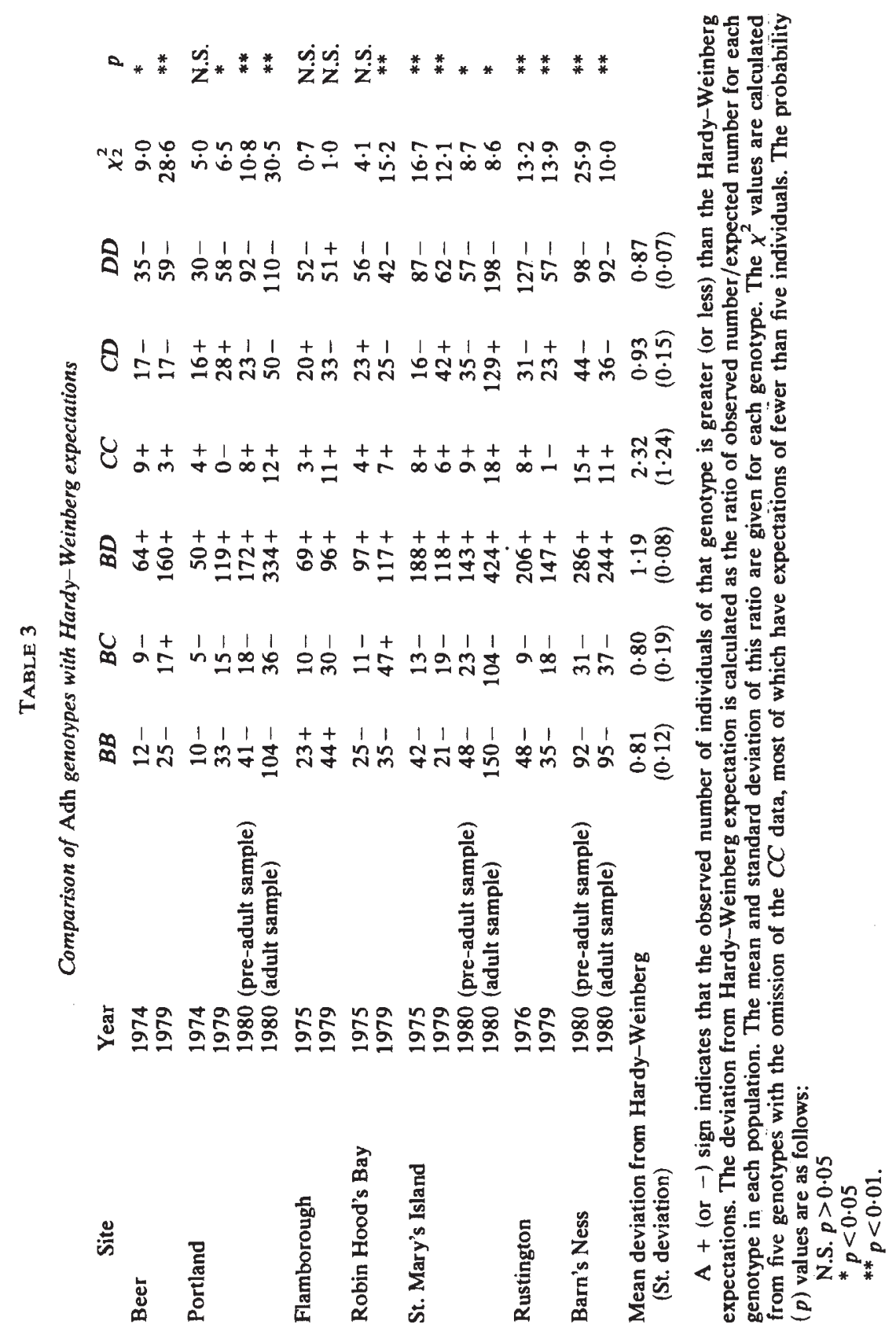


whereas the $C$ allele is found with both sequences. The $A d h$ polymorphism should therefore be interpreted in terms of the inversion polymorphism. We have used the $A d h-B$ and $D$ frequencies to infer the frequencies of the $\alpha$ and $\beta$ inversions. Although the $A d h-C$ allele introduces an inaccuracy, we consider that the advantage of using electrophoresis to obtain larger samples, more than offsets the disadvantages.

There have been many studies of inversion polymorphism from the pioneering work of Wright and Dobzhansky (1946) to more recent studies of linkage disequilibrium between enzyme loci and chromosomal inversions (Kojima et al., 1970; Langley et al., 1974; Mukai et al., 1974; Prakash, 1976; Loukas et al., 1979). These data have most economically been interpreted in terms of natural selection (Prakash and Lewontin, 1968, 1971) although explanations involving founder effects and random genetic drift remain feasible ( $\mathrm{Nei}$ and $\mathrm{Li}, 1980$ ).

If one finds that different populations are not only polymorphic for the same alleles or inversions but carry them at the same equilibrium frequencies, then any explanation relying solely on random effects is unconvincing. Such uniformity between populations is exactly what we have found in seaweed flies. There would appear to be only two types of explanation. Either there is enough migration between populations for them to be effectively a single breeding unit, or populations are isolated and selection independently holds them at the same equilibrium frequency.

To what extent $C$. frigida populations around the British coast are isolated is not known. Dobson (1974a) observed colonisation of a seaweed deposit at a site $12 \mathrm{~km}$ from the nearest known $C$. frigida population, but movement over such distances is exceptional (Dobson, 1974b). The closest pairs of sample sites in this study are Robin Hood's Bay and Flamborough, and Beer and Portland, each over $50 \mathrm{~km}$ apart and separated by coastline unsuitable for Coelopa breeding. Furthermore, the three sites on the east coast of Britain are separated by more than $500 \mathrm{~km}$ from the south coast sites, again with a long stretch of sandy coast $(350 \mathrm{~km})$ supporting no suitable seaweed. Each site can, therefore, be regarded as a distinct population and there can be very little gene exchange, particularly between the east and south coast groups. In spite of this genetic isolation there are no significant differences in gene frequencies between sites individually, nor when grouped geographically.

There are several reasons why we think natural selection is, if not the only force, then at least the major one, maintaining homogeneity. Firstly the $\alpha$ and $\beta$ sequences of chromosome I include at least 180 bands as assessed from salivary gland polytene maps (Aziz, 1975). This inversion involves 5-10 per cent of the entire genome, surely a large enough fraction of all loci for at least one of them to be subject to selection. Secondly, we observe consistent, and often highly significant departures from HardyWeinberg expectations. Excess of heterozygotes and deficiency of homozygotes are not in themselves sufficient to indicate heterosis, but Collins (1978) has shown the $B D(\alpha / \beta)$ heterozygotes have a higher egg to adult viability than either homozygote in the progeny of matings between wild caught $B D$ flies. At high, but not unnatural, densities the viabilities of $B B$ $(\alpha / \alpha)$ and $D D(\beta / \beta)$ homozygotes relative to the heterozygotes were 0.44 and 0.33 respectively. Clearly heterokaryotypic advantage could be a powerful selective force acting on this inversion. 
Finally, the present data suggest the possibility of a temporal change in equilibrium frequency which is consistent between sites. This could be either an annual fluctuation with the frequency of $A d h-B$ (the $\alpha$ sequence) higher in the summer, or a steady increase in the $A d h-B$ allele frequency over the five years or so of this study. Unfortunately we are unable to distinguish these possibilities as there was no indication of either effect from previous observations, and by chance, the year groups differ markedly in their representation of the seasons.

Seasonal changes in inversion frequencies have been observed in Drosophila pseudoobscura and D. persimilis (Dobzhansky, 1948) and have been attributed to fluctuations in the fitnesses of inversion types correlated with environmental parameters, especially temperature. In Coelopa the summer increase in the $\alpha$ sequence could result from seaweed remaining on the beaches for longer in the calm summer months than in the more stormy winter period. Since individuals carrying the $\alpha$ sequence have longer development times (Day et al., 1980), it seems likely that they might enjoy a selective advantage in the summer. Another possibility is that there is a seasonal fluctuation in some features of the habitat to which the inversion polymorphism is responding. There are certainly variations in temperature, humidity and salinity of seaweed deposits, and seasonal changes in several chemical constituents of seaweeds (e.g., mannitol, alginic acid, laminarin) have been described (Black, 1948, 1951 $a, 1951 b$-see also the review by Chapman and Chapman, 1980).

Whatever the cause of the apparent fluctuations in inversion frequencies, the finding that it is consistent in widely spaced populations is compelling evidence for the action of natural selection. A regular sampling programme has been initiated to test the seasonal variation in frequencies.

The possibility remains of a steady year by year increase in the $\alpha$ sequence similar to the trends observed by Anderson et al (1975) in Drosophila pseudoobscura and by Inoue and Watanabe (1979) in $\boldsymbol{D}$. melanogaster. This type of uniform change, whether it results from environmental change or from the formation and spread of a new, adaptively superior, gene complex within the $\alpha$ inversion sequence, is more consistent with the polymorphism being maintained by selection rather than random drift. The geographical uniformity leads us to the same conclusion.

Acknowledgments. - We would like to thank Dr D. T. Parkin and P. C. Hillier who collected some of the samples, and Miss P. Goody who helped with the electrophoresis. The support of the Science Research Council (R.K.B., P.M.C., and T.H.D.) and the Natural Environment Research Council (S.J.S.) is gratefully acknowledged.

\section{REFERENCES}

ANDERSON, W., DOBZHANSKY, T., PAVLOVSKY, O., POWELL. J., AND YARDLEY, D. 1975. Genetics of natural populations. XLII. Three decades of genetic change in Drosophila pseudoobscura. Evolution, 29, 24-36.

AZIZ, J. B. 1975. Investigations into chromosomes 1, 2 and 3 of Coelopa frigida. Ph.D. Thesis, University of Newcastle upon Tyne.

BLACK, W. A. P. 1948. Seasonal variation in the chemical constitution of some of the Laminariaceae common to Scotland. $J$. Soc. Chem. Ind., 67, 165-172.

BLACK, W. A. P. 1951 a. The seasonal variation in weight and chemical composition of the common British Laminariaceae. J. Mar. Biol. Assoc., 29, 45-72. 
BLACK, W. A. P. $1951 b$. The seasonal variation in the cellulose content of the common Scottish Laminariaceae and Fucaceae. J. Mar. Biol. Assoc., 29, 379-387.

BURNET, B. 1961. On the distribution of recessive embryonic lethals in a natural population of Coelopa frigida. Genet. Res., 2, 249-271.

CHAPMAN, V. J., AND CHAPMAN, D. J. 1980. Seaweeds and Their Uses, 3rd edn. Chapman and Hall, London.

COllins, P. M. 1978. Studies on genetic polymorphism in Coelopa frigida. Ph.D. Thesis, University of Nottingham.

DA CUNHA, A. B. 1955. Chromosomal polymorphism in the Diptera. Advances in Genetics, 7, 93-138.

DAY, T. H. 1980. The maintenance of an inversion polymorphism in seaweed flies. Heredity, $45,142$.

DAY, T. H., AND BUCKLEY, P. A. 1980. Alcohol dehydrogenase polymorphism in the seaweed fly Coelopa frigida. Biochem. Genet., 18, 727-742.

DAY, T. H., DOBSON, T., HILlIER, P. C., PARKIN, D. T., AND ClARKE, B. 1980. Different rates of development associated with the alcohol dehydrogenase locus in the seaweed fiy, Coelopa frigida. Heredity, 44, 321-326.

DAY, T. H., DOBSON, T., HILLIER, P. C., PARKIN, D. T., AND CLARKE, B. 1982. Associations of enzymic and chromosomal polymorphisms in the seaweed fly, Coelopa frigida. Heredity, $48,35-44$.

DOBSON, T. 1974a. Mechanisms controlling species composition in natural populations of the seaweed fly Coelopa. J. Nat. Hist., 8,653-673.

DOBSON. T. $1974 b$. Studies on the biology of the kelp fiy Coelopa in Great Britain. J. Nat. Hist., 8, 155-177.

DOBZHANSKY, T. 1948. Genetics of natural populations. XVI. Altitudinal and seasonal changes produced by natural selection in certain populations of $D$. pseudoobscura and D. persimilis. Genetics, 33, 158-176.

DOBZHANSKY, T, 1971. Evolutionary oscillations in Drosophila pseudoobscura. In Ecological Genetics and Evolution, ed. R. Creed, pp. 109-133. Blackwell, Oxford.

EGglishaW. H. J. 1960. Studies on the family Coelopidae. Trans. Roy. Entomol. Soc. London, $112,109-140$.

HARRIS, H. 1980. The Principles of Human Biochemical Genetics, 3rd edn. Elsevier/North Holland Biomedical Press, Amsterdam.

INOUE, Y., AND WATANABE, T. K. 1979. Inversion polymorphism in Japanese natural populations of Drosophila melanogaster. Japanese J. Genet., 54, 69-82.

KOJIMA, K., GILlESPIE, J., AND TOBARI, Y. N. 1970. A profile of Drosophila species enzymes assayed by electrophoresis. I. Number of alleles, heterozygosities and linkage disequilibrium in glucose metabolising systems and other enzymes. Biochem. Genet., 4, 627-637.

LANGLEY, C. H., TOBARI, Y. N., AND KOJIMA, K. 1974. Linkage disequilibrium in natural populations of Drosophila melanogaster. Genetics, 78, 921-936.

LEWONTIN, R. C. 1974. The Genetic Basis of Evolutionary Change. Columbia University Press, New York.

LEWONTIN, R. C., AND WHITE, M. J. D. 1960. Interaction between inversion polymorphism of two chromosome pairs in the grasshopper, Moraba scurra. Evolution, 14, 116-129.

LOUKAS, M., KRIMBAS, C. B., AND VERGINI, Y. 1979. The genetics of Drosophila subobscura populations: Studies on linkage disequilibrium in four populations. Genetics, 93, 497-523.

MUKAI, T., WATANABE, T. K., AND YAMAGUCHI, O. 1974. Linkage disequilibrium in a large population of Drosophila melanogaster. Genetics, 77, 771-793.

NEI, M., AND LI, W.-H. 1980. Non-random association between electromorphs and inversion chromosomes in finite populations. Genet. Res. Camb., 35, 65-83.

NELDER, J. A., AND WEDDERBURN, R. W. M. 1972. Generalized linear models. J. $R$. Statist. Soc. $A, 135,370-384$.

PHILIP, U. 1958. Genetics and cytology of the seaweed fly, Coelopa frigida. Proc. 10th Int. Congress Genet., Montreal 2, p. 217.

PHILIP, U. 1966. Chromosomal polymorphism in Coelopa frigida. Heredity, 21, 167-168.

PRAKASH, S. 1976. Gene differences between chromosome III inversions in Drosophila pseudoobscura. Genetics, 84, 787-790.

PRAKASH, S., AND LEWONTIN, R. C. 1968. Direct evidence of coadaptation in gene arrangements of Drosophila. Proc. Natn. Acad. Sci. USA, 59, 398-405.

PRAKASH, S., AND LEWONTIN, R. C. 1971. Further direct evidence of coadaptation in inversions of Drosophila. Genetics, 69, 405-408. 
SURVER, W. M. 1974. Observations on some aspects of the biology of the kelp fly: Coelopa frigida (Fabricius). Ph.D. Thesis, University of Notre Dame, Indiana.

WRIGHT, S. 1978. Evolution and the Genetics of Populations, Vol. IV, Variability Within and Among Natural Populations, pp. 242-322. Univ. Chicago Press, Chicago.

WRIGHT, S., AND DOBZHANSKY, T. 1946. Genetics of natural populations. XII. Experimental reproduction of some of the changes caused by natural selection in certain populations of Drosophila pseudoobscura. Genetics, 31, 125-156. 